\title{
Commodification of the Sexuality in Kim Kardashian's Instagram Posts
}

\author{
Adib Rifqi Setiawan \\ $\Lambda$ lobatnis Research Society $(\Lambda \mathrm{RS})$ \\ Jl. Kudus - Colo km. 19, Pandak 001/003, Colo, Kudus, 59353, Indonesia \\ adibrifqisetiawan@gmail.com
}

\begin{abstract}
Kim Kardashian is the most famous people on the Earth that is worshipped by many people, including teenage girls, although she has no particular talent to justify her fame, she is entertaining in some way. This research discuss Instagram posts of Kim Kardashian through Gunther Kress and Theo van Leeuwen social semiotics for visual texts, Michael Halliday's transitivity system for written texts, Michael Foucault's panopticon concept in poststructuralism, and Jean Baudrillard's hyperreality. It reveals that Kim Kardashian's Instagram posts represent the discipline of body and sexuality when her portrayals began to be evaluated based on normative standard of society nor selling value of capitalist system.
\end{abstract}

Keywords : hyperreality; Kim Kardashian; panopticon concept; visual texts; written texts;

\section{A. Introduction}

Kim Kardashian is the most famous people on the Earth that is worshipped by many people, including teenage girls, although she has no particular talent to justify her fame, she is entertaining in some way (Setiawan, 2020). Her name used as an index (The Kardashian Index or K-Index), to measure of the discrepancy between a scientist's social media profile and publication record that proposed in 2014 (Hall, 2014). In the society Kim Kardashian is the best at doing action when people don't enjoy celebrities for what they intentionally do, but for what they do unconsciously, like her do in hit show "Keeping Up With The Kardashians" (Setiawan, 2020). Her power make her talk important to listen by public, include academic people, e.g. when she thanked by Armenian Prime Minister Nikol Pashinyan at the government building in Yerevan for promoting Armenia internationally and invited as speaker in the World Congress on Information Technology (WCIT) 2019 in Yerevan, Armenia (On Demand News, 2019; CIVILNET, 2019).

Driven by the depiction of Kim Kardashian's success, the viewers begin to enter the phase where they wish to become as success as the portrayal of the successful internet celebrities. Depicted as the role models, these celebrities will 'behaviourally dictate and domesticate' their viewers by bringing out the depiction of idealized appearances and body images (Juntiwasarakij, 2018, p. 555). Kim Kardashian is the person who have more power to influence the viewers, that can manage to normalize her identity, including the body and sexuality, as well as social practices shown off on the social media as being 'more accessible, common, and traditional'. Thus, the target viewers will come into a point where they have gained emotional attachment with these internet celebrities. The process of normalizing internet celebrities' identity into gaining emotional attachment from the viewers went through the concept of media equation, that social response automatically emerges when it is related to human characteristics, e.g. human appearance on the screen, and the viewers respond to the communication media as if it is real social actors. When emotional attachment has come with the trust from the viewers, they will later be struggling for being liked or shared in the connected society through sharing their intimate personal information on social media. 
In controlling the society through the medium of the body and sexuality, a process of normalization emerges since the body and sexuality have become the powerful platforms to experience the world and to express the existence of the self in society. The process of normalizing the body and sexuality went through the process of disciplining the corporeal body or material body; the body is monitored through disciplinary power (Foucault, 1975, p. 8). The corporeal body will be under the rules of the society which seek to regularize. These norms and rules urge the body to become docile (docile body), as if the body belongs to the system of prison or is called the concept of panopticon. Panopticon concept plays its role as a constant observation and control to the body, so the body will always be under constant surveillance until the body becomes docile (docile body).

Some women represent themselves on social media by showcasing more sexually appealing images because it is believed in giving a sense of empowerment for them through being appreciated and admired sexually (Liss, Erchull, \& Ramsey, 2010, p. 65). On the other hand, revealing the bodies or showing sexual attractiveness through images as a result of body surveillance can also be addressed as sexual exploitation in which women are used as sexual properties to become the viewers' consumption and to deliver sensual pleasure to the viewers (Rudman \& Hagiwara, 1992, p. 87). This process will lead to a concept named sexualization, and sexualization happens where women are only evaluated by the viewers limited to their sexual appeal. Some of these women have believed that wearing revealing clothing will boost up their confidence as well as is considered successful in taking control of their body and sexuality.

Projecting women image and body, however, could also dehumanize women if they are functioned only to be looked at and evaluated by the viewers since their representation on the images is becoming more important rather than their value as a person, and this also reconfirms the process to the concept of selfobjectification. The viewers will see these women as sexual objects because of their sexual appeal; when it creates pleasure to the viewers and is rated as sexual object, they become objectified. When the viewers only focus on exposing sexual appeal through the body and sexuality on images, it is where women's body parts and sexual functions are separated over its entire functionality and value as a person.

This research discuss Instagram posts of Kim Kardashian through Gunther Kress and Theo van Leeuwen social semiotics for visual texts (photos) and Michael Halliday's transitivity system for written texts (captions) to uncover the structuralist meanings on every Instagram post (Kress \& Leeuwen, 2006; Halliday \& Matthiessen, 2004). Moreover, Michel Foucault's panopticon concept in poststructuralism as well as Jean Baudrillard's hyperreality were deployed to dismantle the process of normalization of the body and sexuality (Foucault, 1975; Baudrillard, 1994).

These analyses of both visual and written texts will be integrated to see how the image and caption from every Instagram post contradict to her caused by the process of normalization and commodification of the body and sexuality. Textual analysis and text-based qualitative research design were used to analyze both the visual and written texts. How Kim Kardashian's Instagram posts (photos and captions) dismantle the process of normalizing the body and sexuality is the question in which the answer will be found throughout this research. 


\section{B. Methods}

This research used qualitative approach, specifically, the text-based qualitative research design and was conducted through textual analysis. This research deployed the stratified purposive sampling technique to analyze 2 Instagram posts of Kim Kardashian. This sampling technique was used to choose the sample according to the needs of the research, specifically Instagram posts of Kim Kardashian was linked and related to the issue of normalization of the body and sexuality. The data of the study are photos and captions from Kim Kardashian's Instagram posts. The data source of this study came from Kim Kardashian (@kimkardashian) selected Instagram posts. The data were collected by visiting Kim Kardashian's Instagram accounts, observing the pattern of these celebrities in exposing their body and sexuality, and determining photos and captions. The data were analyzed by classifying them into two big groups: visual text and written text analyses. In a structuralist approach, visual texts were analyzed by deploying social semiotics theory by Gunther Kress and Theo van Leeuwen, and written texts were analyzed by deploying Michael Halliday's transitivity theory (Kress \& Leeuwen, 2006; Halliday \& Matthiessen, 2004). These structural analyses, then, were again analysed by employing Michel Foucault's panopticism in poststructuralist approach and Jean Baudrillard's hyperreality in postmodernism (Foucault, 1975; Baudrillard, 1994). The procedure of analyzing the data was conducted through two layers. The first layer focuses on examining Kim Kardashian's Instagram posts using Gunther Kress and Theo van Leeuwen's social semiotics and Michael Halliday's transitivity system to uncover the meanings in a structuralist level. The second layer focuses on examining Kim Kardashian's Instagram posts using Michel Foucault's panopticism in post-structuralism theory and Jean Baudrillard's hyperreality in postmodernism to dismantle the process of normalization of the body and sexuality.

\section{Findings}

From instagram posts of Kim Kardashian, the research revealed that she was portrayed in a revealing manner, and it is not limited only to the daily contents, but also to promotional contents. Some instagram posts of Kim Kardashian showed no connection between the products being advertised on the caption and the focus elements on the image - the revealing body and sexuality. Kim Kardashian commodified her inner lust and sexual appeal which was emanated from her body and sexuality for a purpose in selling her personal businesses' products. The commodification occurred through the process of Kim Kardashian normalizing her body and sexuality by being imprisoned under constant surveillance from a capitalist system, the viewers, and herself. Applying the tight, revealing fashion style and other seductive attributes to the body, undertaking some workouts and cosmetic surgeries, having her photos edited before her Instagram posts were published were Kim Kardashian's choices in making her body imprisoned.

\section{Discussion}

\section{Visual and Written Texts}

In visual text, the focus of the image is taking place mostly on Kim Kardashian's revealing body and her sexuality through sexually stimulating pose and gestures as well as displaying as if the image has its imaginary narration of she being ready for sexual activity on the bed; she is portrayed in an almost naked pose within only underwear being attached to her body. Kim Kardashian is lying down atop the blossoms and is bending her right leg on the image. It 
creates a sense of a man is having his authority over Kylie's body on the image (Stephenson, 2015 , p. 98). Moreover, bending the leg would make her feet appear longer, and it automatically made Kim Kardashian curved her back a little (Rowse, 2012). As a result of bending her leg and curving her back, it accentuates the shape of her breasts, waist, and hips; the viewers would clearly see Kim's overall hourglass figure. Moreover, even though the pink blossoms would create the bright spot whenever the viewers see them on the image, the blossoms are still considered softer in colour rather than Kim's tanned skin colour; it makes Kim as a represented participant brings the most vital information and message of the image.

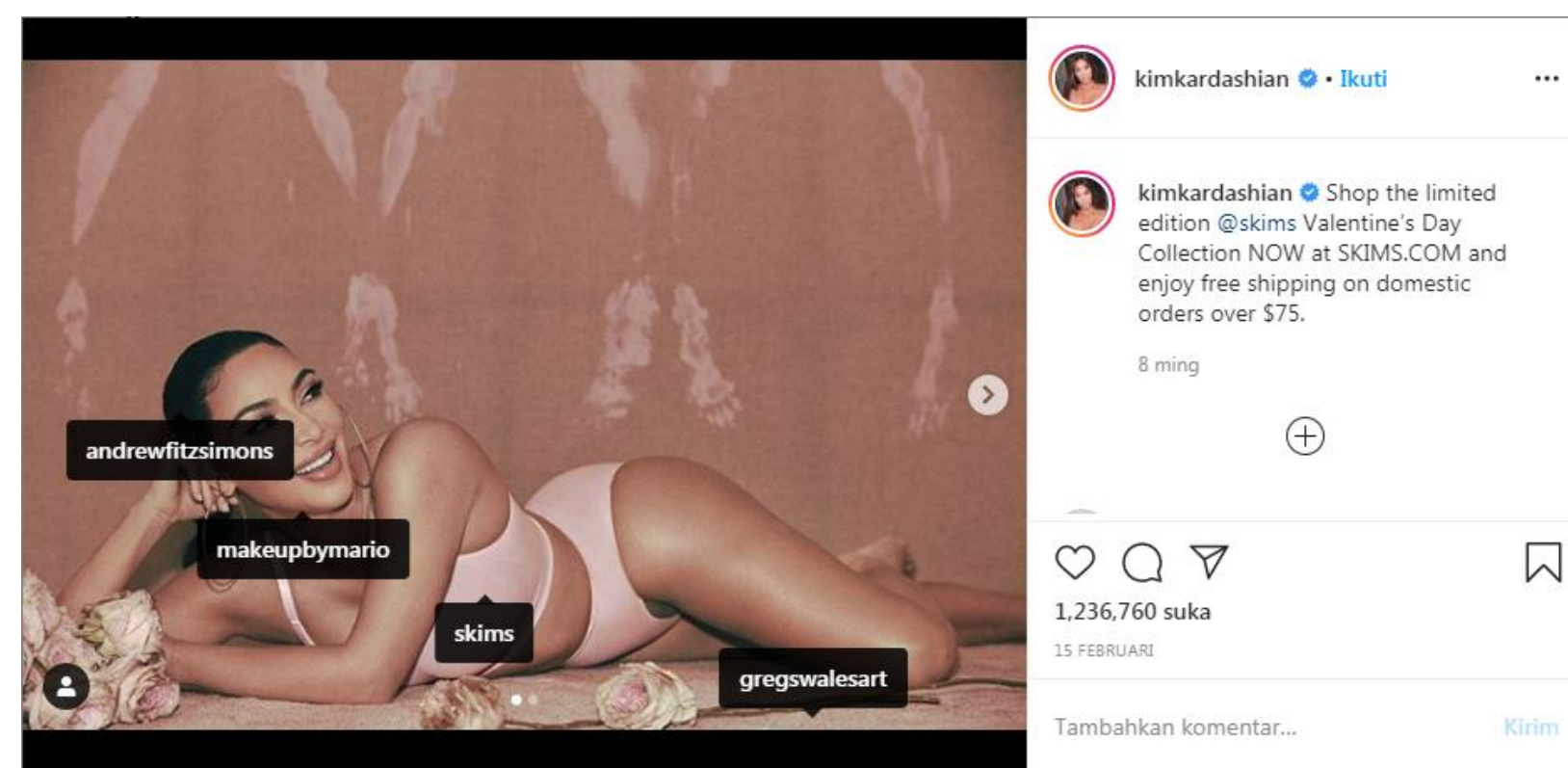

Figure 1. Kim Kardashian's Instagram post on February 15, 2020 (Kardashian, 2020).

However, the caption has its central purpose in promoting Kim Kardashian's products from SKIMS, SKIMS Valentine's Day. The caption carries both of a material process and relational process since Kim urges the viewers to do something - to buy the products from SKIMS Valentine's Day. In addition, SKIMS Valentine's Day as the carrier in the caption has its attribute that describes the products, Classic Bottom Collection, in which the information described on the caption is about the availability of the newest products at Kim Kardashian's SKIMS website. Capital letters would also seem to guide the viewers to have their primary focus and attention to it. However, the use of triple exclamation marks function to deliver a feeling of Kim's excitement to the viewers regarding the release of SKIMS Valentine's Day products. On overall analysis of written text, besides promoting the new products from her personal business, Kim also instructs the viewers to purchase the products in her literal language through the use of the command 'NOW at SKIM.COM'. The caption still has its central aim to advertise SKIMS Valentine's Day.

Integrating the visual text and written text, even though both analyses portray the elements of blossoms, the visual and written text analyses lack of its connection in meaning. There is a contradiction between these two analyses since visual text has its central focus on showcasing Kim Kardashian's revealing body and sexuality through some seductive pose and gestures. Meanwhile, the caption aims to only promote and to advertise the newest products from Kim Kardashian's personal business brand. If Kim Kardashian has her intention to exclusively promote the products, she must have given the focus and highlight on the image more on her face since the eyeshadow palette, lipsticks, liners, and blushes are only applicable to her face. 
Kim Kardashian's make-up colour on her face does not get salience and blends with the overall colour of her skin.

In conclusion, Kim uses the strategy of gluing her inner lust and sexual appeal which are emanated through her body and sexuality to the products she is promoting on Instagram post. As a result, the seductive representation and persona from Kim Kardashian would later guide the viewers' perceptions that these products would help them, especially the targeted-female market, in getting similar seductive look like Kim Kardashian if they purchase the products (Black \& Morton, 2015, p. 335). Furthermore, Kim Kardashian's seductive persona is also in its aim to deliver pleasure for male viewers.
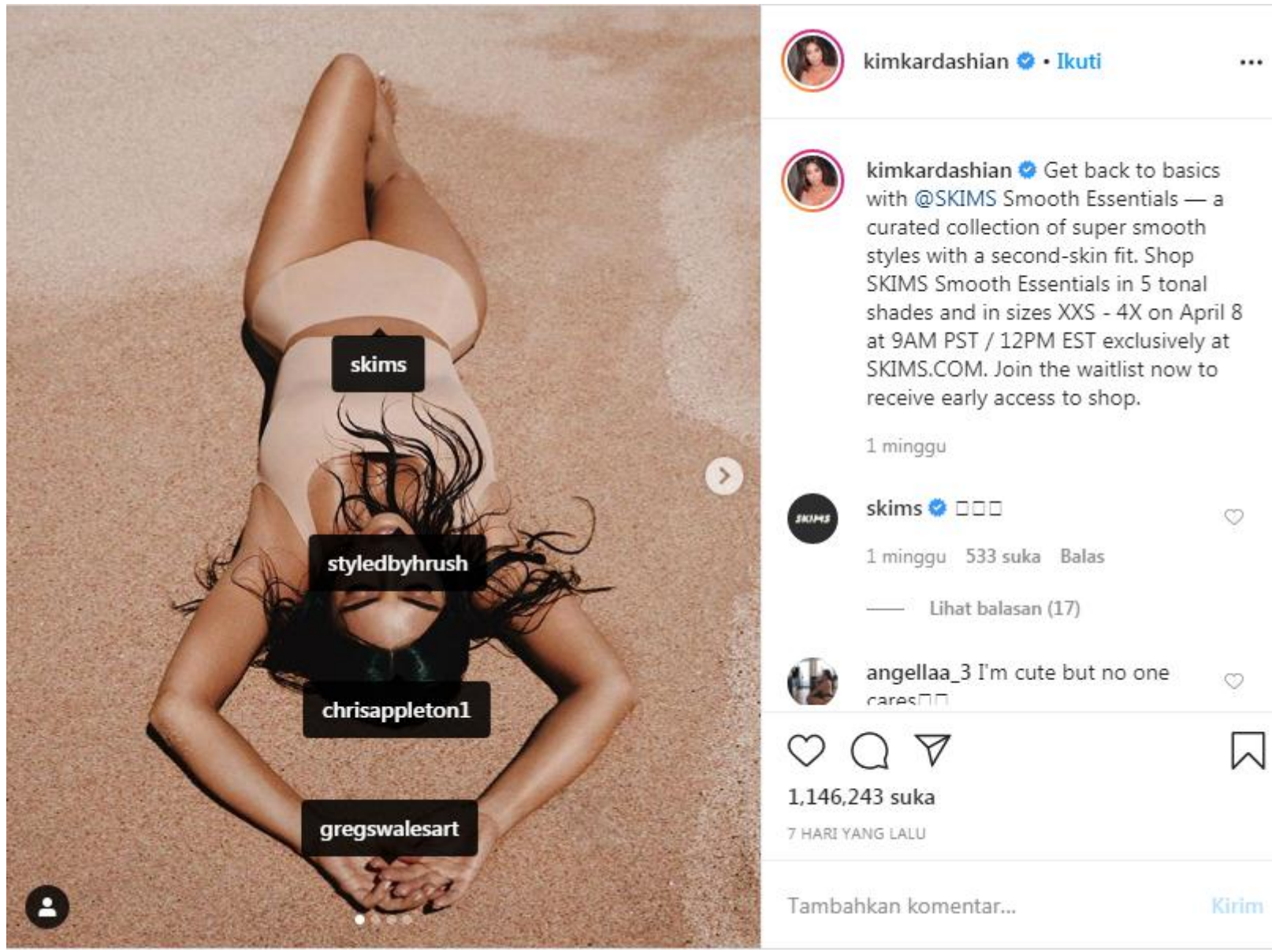

Figure 2. Kim Kardashian's Instagram post on April 6, 2020 (Kardashian, 2020).

From the visual text, the central focus of Figure 1 takes place on Kim Kardashian's body and sexuality since the portrayal of her pose in a revealing manner highlights the narration of the image. On Figure 2, a sleeveless bodysuit is being the biggest attribute attached on Kim Kardashian's body.

For practical and fashion reasons, a bodysuit has its central function to control and reshape the whole body since a bodysuit is a combination between brassiere, waist nipper and girdle. A bodysuit, through its elasticity, will not make its material shifting, so a bodysuit would create the tight look around the breasts, waist, tummy, and thighs (Setiawan, 2018). The preference on wearing a sleeveless bodysuit with a scoop neckline in which the neckline is cut low enough also implies that Kim Kardashian's intends to display her curves as well as her cleavage. 
Moreover, the seductive pose of placing her hands above her head creates the breasts to stick out and makes her armpits being easily spotted by the viewers; these are able to lure the viewers' eyes and attention (Setiawan, 2018). Biologically, human armpits are rich in pheromones, the chemical messengers which have its role in being the opposite-sex attractants or have its specific role in sexual arousal (Grammer, Fink, \& NickNeave, 2005, p. 136). Tilting the head and revealing the neck at the same time while positioning the hands above the head can also be read as a sign of women's submissiveness yet this pose is more alluring to men; it refers to how men are in their authority towards women (Hanna, 2012, p. 210). Kim Kardashian's flirting behaviour through pouting her lips also adds up her seductiveness as if she makes the first move (Givens, 1978, p. 351). However, the caption on Figure 2 has its central purpose on promoting her upcoming product SKIMS Smooth Essentials. The caption of Figure 1 is a pure promotional content or advertisement. Figure 2's photo caption carries a mental process since Kim Kardashian's intends to express her term of affection to wear this product.

Based on the image and caption analyses, the visual text and written text do not connect to each other. The contradiction between both the image and caption is found since the image has its central focus on Kim Kardashian's sexual appeal as well as her seductive elements and gestures which are emanated through her body and sexuality, while the caption's primary focus lies on its promotional purpose to promote her business product. From the overall interpretation, Kim Kardashian would seem to use the strategy of gluing her seductive portrayal first to get the viewers' attention. She utilizes her inner lust and sexual appeal which emerge from her body to promote her SKIMS Smooth Essentials. If Kim Kardashian intends to purely promote her personal business brand, she could have used some salient elements attached on her bodysuit since it must be the central focus of what she is trying to sell to the public. Nevertheless, Kim Kardashian chooses to focus more on her body and sexuality through seductive gestures on the image, perceiving her seductive portrayal is an effective strategy in attracting the viewers' attention. Targeting to the female viewers, Kim Kardashian's portrayal would seem to urge the viewers to have similar seductive look like her, while her depiction helps to reinforce her sexual appeal to be looked at by the male viewers (Black \& Morton, 2015, p. 4).

Based on visual text and written text, the image and the caption on Figure 3 have their connection to each other. On the image, the use of her skirt and some of her satisfaction gestures help Kim Kardashian's action in revealing her body and expressing her sexuality in public; she would seem to deliver her sexual appeal to the viewers' eyes through the depiction of her sexually stimulating body. Kim Kardashian's skirt on the image has its symbolic function as a body shaper, and it allows she as the wearer to cinch and to reduce her waist as well as to smooth her shape to look like an womankind figure. Through such depiction of Kim Kardashian loosens her shoulder straps, Kim Kardashian would seem to intend showing the shape of her breasts and delivering her sexual appeal to the viewers. In addition, a skirt has its vital function to cover up as well as to accentuate the hips and buttocks since it has a narrow cut to the body. Wearing a skirt makes women's legs appear to be more attractive, that also suggest that the woman has grown up in a healthy environment, and it produces a positive effect on women's fertility (Sorokowski \& Pawlowski, 2008, p. 86). This scientific rationale supports the idea of Kim Kardashian on Figure 3 is wearing a skirt because it accentuates the apparent leg length for her, and it incites both men and women's attention to look only at the revealing parts of what she has portrayed on the image. 
Connecting Kim Kardashian's woman kindness with the caption, the caption of Figure 3 which consists of behavioural process would seem to support the main purpose and idea of the overall that instagram post. On the caption, Kim Kardashian asserts the viewers to focus on the 'Quick Change...'. Incorporating the term of 'Quick Change...' with the image, Kim Kardashian is reflecting its term to the image as if one of the quick change Kim Kardashian had is her journey - her experience in Paris that made her a different person, as she told in The Ellen Show on 27 April 2017, as well as her evolution from Paris Hilton's assistant until personal competition between the two that still going strong years later (Keeping Up With The Kardashians, 2019; TheEllenShow, 2017; Setiawan, 2016).
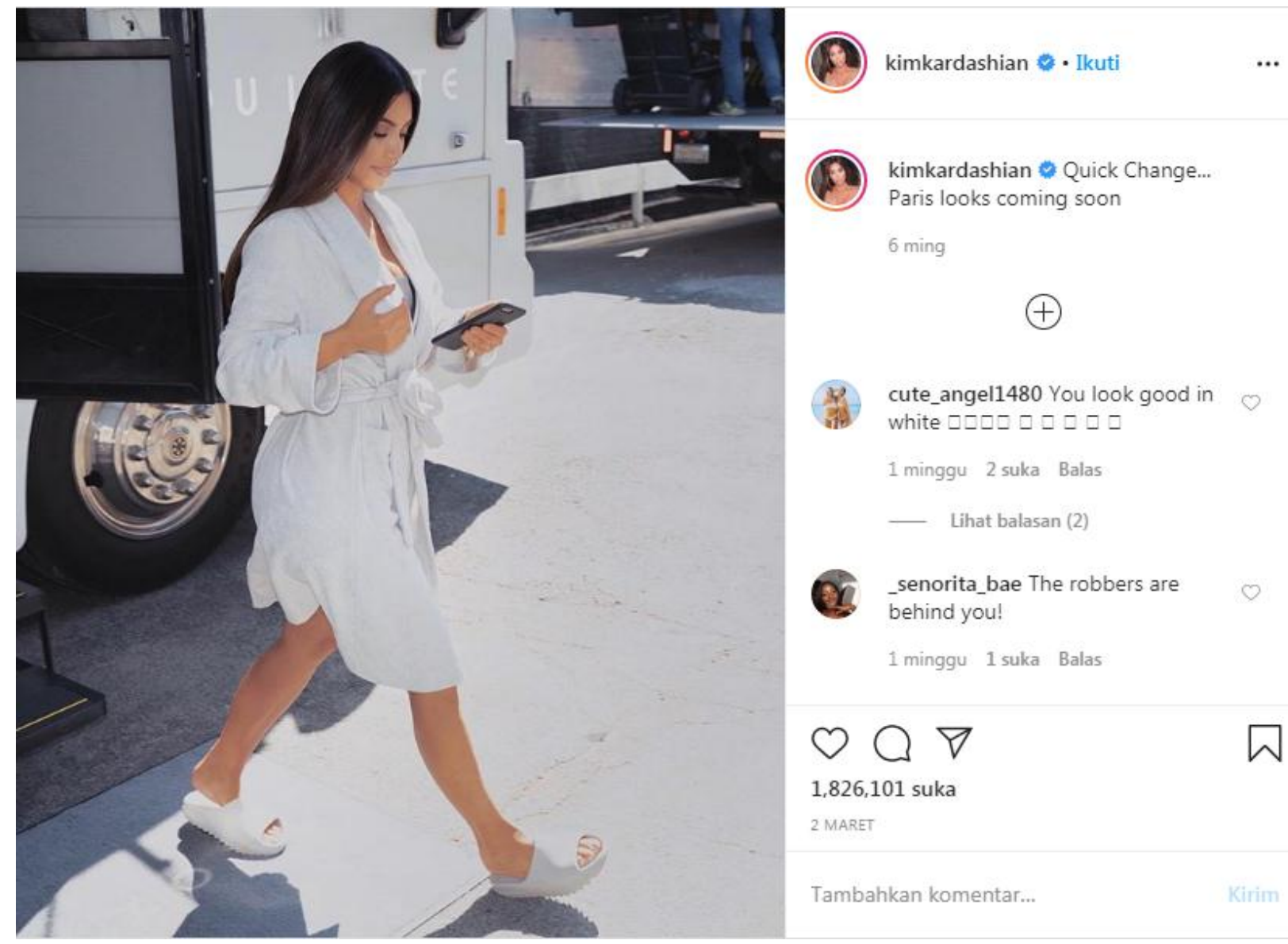

Figure 3. Kim Kardashian's Instagram post on March 2, 2020 (Kardashian, 2020).

\section{Normalization of the Body and Sexuality}

An exposed body has become a space of a liberating expression of a woman's sexuality and is considered as a part of a woman's self-identity in Western culture (Amin, 2015, p. 47). Kim Kardashian, who have her power over her corporeal body, is often caught up in wearing tight, revealing clothes on her Instagram posts. From an overall analysis, the choices of wearing a bodysuit and skirt, eventually shaped Kim Kardashian's body to look like an attractive, focusing on some of her special body parts which are able to deliver her sexual appeal through some seductive gestures and poses, including breasts, waist, hips, thighs, buttocks, and armpits. However, the urgency of exposing their body and sexuality in public through the choice of wearing revealing clothing and using some of sexually stimulating attributes on almost every Instagram post would make the viewers seeing Kim Kardashian's representation as a normal, typical portrayal of influencers (Glucksman, 2017, p. 85). 
Furthermore, facing the recent condition of which sex appeal advertisement is effective in generating consumers' attention, Kim Kardashian use this kind of strategy to reach out to millions of the viewers' eyes. Kim Kardashian is presented as figures to emulate, suggesting her stereotyped curvaceous body and sexuality could perform as an effective marketing strategy in selling the products she is promoting through her seductive aura and persona of her lust, seductive manner, and sexual appeal (Poorani, 2012, p. 10). When promotional activity has made Kim Kardashian's body and sexuality part of an ideal package, her representation is ready to be exchanged with some personal profits; in this case, she worth a lot of money, and she will be transformed into a commodity. As a result, even though it is nearly impossible to make all viewers, especially female-targeted market, to purchase the products or services Kim Kardashian is promoting, the most important matter is the viewers have unconsciously obtained and bought the idea of a new set of standards regarding beauty and body ideals from her portrayals on her Instagram posts; unconsciously, this female viewers would be in a process of internalizing her bodies through the exposure to their portrayals on the image (Poorani, 2012, p. 10). While white women tend to idealize thin body type, Kim Kardashian rather choose to desire and to create a trend on a curvaceous body type; it determines her position in the society for being a trendsetter (Overstreet, Quinn, \& Agocha, 2010, p. 91). Up to this phase, Kim Kardashian have successfully normalized her sexually stimulating standardization of the body and sexuality to the viewers' eyes.

Within the process of normalization, Kim Kardashian, through exemplifying herself in a revealing manner, is positioned as a subject since she is being the doer in her action of normalizing the body and sexuality. In normalizing the body, as a subject, Kim Kardashian discipline, rule, control, and monitor her body; the body gets disciplined and monitored through some manners, including through wearing revealing clothing. This is also considered as Kim Kardashian's exercise of her disciplinary power, and it transforms the body to become docile (Foucault, 1975, p. 8). Kim Kardashian's docile body will always be under the rules in which these rules always continue to force and demand her to showcase her body in public by wearing revealing, tight clothing in a seductive gestures and pose since revealing manner in Western culture is still considered as an effective strategy to gain the viewers' attention. However, the fact that Kim Kardashian always sold their products of her business brands on the first day of its release date shows that the viewers' responses were enthusiastic, and these enthusiastic responses from the viewers indicate that the strategy of promotional content focusing on Kim Kardashian's persona of her inner lust and sexual appeal from her body and sexuality has been successfully executed. These positive, enthusiastic responses from the viewers also add up more rationale of why Kim Kardashian need to always control and monitor her seductive persona; wearing an intentional, tight clothing as well as portraying seductive gestures and pose as the process of normalization will impose the body as if the body is inside a prison system or is called panopticon (Foucault, 1975, p. 8).

However, monitoring the body cannot be emanated only through the revealing style of fashion that Kim Kardashian wore on the image, but it can also be acquired through external activities. Kim Kardashian have declared herself that she has gone through several cosmetic surgeries, including surgeries on her breasts, buttocks, hips, and thighs, and it is proven by celebrity dermatologist and plastic surgeon; she is also doing several external activities to maintain their curves, such as undertaking cosmetic surgeries, strict diet, and some exercises focusing on fitness, weight loss, and core strength (Setiawan, 2020). These activities are other evidences that Kim Kardashian is proven in making her body being under the surveillance and constant observation as if she is putting in her body inside a prison system. 
From an overall interpretation of Kim Kardashian being the subject of her process of normalization, she manage to utilize her inner lust and sexual appeal from the medium of her body and sexuality as a promotional content to advertise some services and products. Nevertheless, she do not truly sell her body and her sexuality to promote the products, rather it is her inner lust and sexual appeal from her body and sexuality which establish the viewers' responses. As a result, female viewers would activate their self-improvement goal towards Kim Kardashian's seductive portrayals, while male viewers tend to respond more favourably to sexual appeal appeared on the image (Setiawan, 2018, p. 17). In shorter words, Kim Kardashian would seem to make male viewers want her and to make female viewers want to have similar seductive, sexually appealing look like Kim Kardashian.

On the other hand, Kim Kardashian is also positioned as an object under a capitalist system in an economic and social use through visual and written languages on the image. In an economic use, she is presented on the image as if they are accustomed to deliver unblemished persona to the viewers through her body and sexuality as a strategy to sell the products. Kim Kardashian's choices on wearing a tight, revealing clothes as well as expressing some seductive gestures and poses indicate that they intend to expose her perfect curves and body shape, so she could perfectly exhibit and deliver her inner lust and sexual appeal to the viewers (Hakim, 2010, p. 499). As a result, this action unfolds the opportunity to commodify her sexual appeal of which it is emanated through her body and sexuality; Kim Kardashian's representation is exchanged with personal profits (Setiawan, 2018). However, in a social use, Kim Kardashian become an object to the viewers' eyes since her representation on Instagram posts is later being evaluated by the viewers on Instagram (Setiawan, 2018). Before Kim Kardashian become a sexual object in the viewers' eyes, she get sexualized by the viewers. Sexualization is considered as the viewers' response towards the representation of Kim Kardashian who is focusing only to deliver her sexual appeal to her Instagram posts; the viewers would view her representation limited only to their sexual attractiveness (Ward, Seabrook, Grower, Giaccardi, \& Lippman, 2017, p. 31). As a result, the viewers will only look at Kim Kardashian based on her sexual appeal on the image. While sexualization appears, the viewers would evaluate her representation on the image as a sexual object; at this phase, Kim Kardashian becomes objectified (Fredrickson \& Roberts, 1997, p. 176). (Fredrickson \& Roberts, 1997, p.3).

From an overall process of Kim Kardashian normalizing her body and sexuality, the elements portrayed reveal that she is hyperreal (Baudrillard, 1994, p. 11). Kim Kardashian's portrayals on her Instagram posts are just a simulation of a new set of unattainable standards to aspire by the viewers which precede the real as if the representation of she is a real social actor who is capable in affecting real people. At the first stage of simulation, Kim Kardashian would seem to only portray the characteristic of Western culture in representing the self in a revealing manner. However, since her primary intention is to make the viewers purchasing their products, she exaggerate some elements that are being the focus of attention, including her body and sexuality, through the choices of clothing as well as sexually stimulating gestures and poses, undergoing some workouts and cosmetic surgeries, and having a retouch of Photoshop on the image before the images were published. At this stage, Kim Kardashian have blurred the viewers' perceptions of the 'real' because she have masked her 'reality' by normalizing the new constructed beauty and body ideals through accentuating her curves and seductive sexuality to the viewers. As a result, the viewers can no longer distinguish between the 'real' representation of Kim Kardashian and the simulacrum shown off on her Instagram posts. 


\section{E. Conclusion}

This research sought to dismantle the process of body and sexuality normalization in the lives of Kim Kardashian as an internet celebrity. Theoretical perspectives drawn from Gunther Kress and Theo van Leeuwen social semiotics for visual texts (photos), Michael Halliday's transitivity system for written texts (captions), Michael Foucault's panopticon concept in poststructuralism, and Jean Baudrillard's hyperreality were used to reveal that Kim Kardashian's Instagram posts represent the discipline of body and sexuality when her portrayals began to be evaluated based on normative standard of society nor selling value of capitalist system (Kress \& Leeuwen, 2006; Halliday \& Matthiessen, 2004; Foucault, 1975; Baudrillard, 1994). Hence, Kim Kardashian had her body surveillance through wearing some tight, revealing clothing, undertaking some physical exercises and cosmetic surgeries, nor attaching some sexually stimulating attributes and gestures to the body in order to always look ideal in the viewers' eyes.

As a result, her body became imprisoned, and the viewers only viewed Kim Kardashian as a sexual object of which Kim Kardashian put on more focus limited only to showcase her sexual appeal on social media. Kim Kardashian's seductive lust and sexual appeal which were emanated from her body and sexuality then became exchanged with some personal profits through promotional Instagram posts, and it is when she became commodified. Moreover, her representation on Instagram posts serves only a simulation of what Kim Kardashian wished to portray; her representation on Instagram is no longer the 'real' representation of her, or it is just a hyperreal.

\section{Acknowledgment}

This work is dedicated to my wife in the making, Wahyu Eka Saputri, of her endless inspiring and motivating my research.

\section{References}

Amin, A. (2015). Conflicts of Fitness: Islam, America, and Evolutionary Psychology. Morrisville: Lulu Press.

Baudrillard, J. (1994). The Precession of Simulacra. University of Michigan Press: Michigan. Black, I. R., \& Morton, P. (2015, January 16). Appealing to men and women using sexual appeals in advertising: In the battle of the sexes, is a truce possible? Journal of Marketing Communications, 331-350.

CIVILNET. (2019, October 8). Kim Kardashian speaks at WCIT 2019. Retrieved April 15, 2020, from YouTube CIVILNET: https://youtu.be/xIZattYCttg

Foucault, M. (1975). Surveiller et punir : Naissance de la prison. Paris: Éditions Gallimard. Fredrickson, B. L., \& Roberts, T.-A. (1997, June 1). Objectification Theory: Toward Understanding Women's Lived Experiences and Mental Health Risks. Psychology of Women Quarterly, 21(2), 173-206.

Givens, D. B. (1978). The Nonverbal Basis of Attraction: Flirtation, Courtship, and Seduction. Psychiatry Interpersonal and Biological Processes, 41(4), 346-359.

Glucksman, M. (2017). The Rise of Social Media Influencer Marketing on Lifestyle Branding: A Case Study of Lucie Fink. Elon Journal of Undergraduate Research in Communications, 8(2), 77-87. 
Grammer, K., Fink, B., \& NickNeave. (2005, February 1). Human pheromones and sexual attraction. European Journal of Obstetrics \& Gynecology and Reproductive Biology, $118(2), 135-142$.

Hakim, C. (2010, March 19). Erotic Capital. European Sociological Review, 499-518.

Hall, N. (2014, July 30). The Kardashian index: a measure of discrepant social media profile for scientists. Genome Biology, 15(7), 424.

Halliday, M. A., \& Matthiessen, C. (2004). An Introduction to Functional Grammar. London: Arnold.

Hanna, J. L. (2012). Empowerment: The Art of Seduction in Adult Entertainment Exotic Dance. In F. Kouwenhoven, \& J. Kippen, Music, Dance and the Art of Seduction (pp. 197-221). Delft: Eburon Academic Publishers.

Juntiwasarakij, S. (2018, September-December). Framing emerging behaviors influenced by internet celebrity. Kasetsart Journal of Social Sciences, 39(3), 550-555.

Kardashian, K. (2020, April 6). Get back to basics with @ SKIMS Smooth Essentials - a curated collection of super smooth styles with a second-skin fit. Shop SKIMS Smooth Essentials in 5 tonal shades and in sizes XXS - 4X on April 8 at 9AM PST / 12PM EST exclusively at SKIMS.COM. Join the. Retrieved April 15, 2020, from Instagram Kim Kardashian: https://www.instagram.com/p/B-mvkJ3A9Go/

Kardashian, K. (2020, March 2). Quick Change... Paris looks coming soon. Retrieved April 15, 2020, from Instagram Kim Kardashian: https://www.instagram.com/p/B9M0hztg_7Y/

Kardashian, K. (2020, February 15). Shop the limited edition@skims Valentine’s Day Collection NOW at SKIMS.COM and enjoy free shipping on domestic orders over \$75. Retrieved April 15, 2020, from Instagram Kim Kardashian: https://www.instagram.com/p/B8jgz67A2fj/

Keeping Up With The Kardashians. (2019, August 18). Kim Kardashian Thanks Paris Hilton For Her Career | KUWTK Exclusive Look | E! Retrieved April 15, 2020, from YouTube Keeping Up With The Kardashians: https://youtu.be/M84U7Yv6DAc

Kress, G., \& Leeuwen, T. v. (2006). Reading Images: The Grammar of Visual Design (2nd ed.). London: Routledge.

Liss, M., Erchull, M. J., \& Ramsey, L. R. (2010, October 14). Empowering or Oppressing? Development and Exploration of the Enjoyment of Sexualization Scale. Personality and Social Psychology Bulletin, 37(1), 55-68.

Na, M. (2017). Wearing Effectiveness of Bodysuit Pattern on Golden Body Proportion. Journal of Advanced Research in Dynamical and Control Systems, 67-74.

On Demand News. (2019, October 11). Kim Kardashian West Thanked for Promoting Armenia Internationally. Retrieved April 15, 2020, from YouTube On Demand News: https://youtu.be/CAdL43si5Bc

Overstreet, N. M., Quinn, D. M., \& Agocha, V. B. (2010, May 07). Beyond Thinness: The Influence of a Curvaceous Body Ideal on Body Dissatisfaction in Black and White Women. Sex Roles, 63, 91-103.

Poorani, A. (2012). Who determines the ideal body? A Summary of Research Findings on Body Image. New Media and Mass Communication, 1-12.

Rowse, D. (2012, April 22). Posing Guide: 21 Sample Poses to Get You Started with Glamour Photography. Retrieved April 15, 2020, from Digital Photography School: https://digital-photography-school.com/posing-guide-21-sample-poses-to-get-youstarted-with-glamour-photography/

Rudman, W. J., \& Hagiwara, A. F. (1992). Sexual Exploitation in Advertising Health and Wellness Products. Journal Women \& Health, 18(4), 77-89. 
Setiawan, A. R. (2016, February 17). PARIS. Retrieved April 15, 2020, from

Alobatnic.blogspot.com: http://alobatnic.blogspot.com/2016/02/paris.html

Setiawan, A. R. (2018, March 05). Breast Capital. Retrieved April 15, 2020, from

Alobatnic.blogspot.com: http://alobatnic.blogspot.com/2018/03/breastcapital.html

Setiawan, A. R. (2018, April 10). Eny Rochmawati Octaviani. Majalah SANTRI, pp. 15-18.

Setiawan, A. R. (2018, January 1). Pantat Perekat Umat. Retrieved April 15, 2020, from Alobatnic.blogspot.com: http://alobatnic.blogspot.com/2018/01/pantat-perekatumat.html

Setiawan, A. R. (2018, March 09). Venice Min. Retrieved April 15, 2020, from Alobatnic.blogspot.com: https://alobatnic.blogspot.com/2018/03/venice-min.html

Setiawan, A. R. (2020, March 28). Behind the Celebrity Worship on Kim Kardashian Case. Retrieved April 15, 2020, from Alobatnic.blogspot.com: https://alobatnic.blogspot.com/2020/03/kim.html

Setiawan, A. R. (2020, March 22). The Impact of the Kardashians on Modern Society. Retrieved April 15, 2020, from Alobatnic.blogspot.com: https://alobatnic.blogspot.com/2019/03/the-impact-of-kardashians-on-modern.html

Sorokowski, P., \& Pawlowski, B. (2008, March). Adaptive preferences for leg length in a potential partner. Evolution and Human Behavior, 86-91.

Stephenson, P. (2015). Foundations of Posing: A Comprehensive Guide for Wedding and Portrait Photographers. Amherst: Amherst Media.

TheEllenShow. (2017, April 17). Kim on How the Paris Incident Changed Her Life. Retrieved April 15, 2020, from YouTube TheEllenShow: https://youtu.be/TzKeiCfHVu0

Ward, L. M., Seabrook, R. C., Grower, P., Giaccardi, S., \& Lippman, J. R. (2017, December 13). Sexual Object or Sexual Subject? Media Use, Self-Sexualization, and Sexual Agency Among Undergraduate Women. Psychology of Women Quarterly, 42(1), 2943. 